Mots. Les langages du politique

\title{
Émotion populaire, petite note lexicologique
}

\section{Maurice Tournier}

\section{OpenEdition}

\section{Journals}

Édition électronique

URL : https://journals.openedition.org/mots/3483

DOI : $10.4000 /$ mots.3483

ISSN : 1960-6001

\section{Éditeur}

ENS Éditions

\section{Édition imprimée}

Date de publication : 1 juillet 2004

Pagination : 121-125

ISBN : 2-84788-057-7

ISSN : 0243-6450

\section{Référence électronique}

Maurice Tournier, «Émotion populaire, petite note lexicologique », Mots. Les langages du politique [En ligne], 75 | 2004, mis en ligne le 22 avril 2008, consulté le 23 avril 2022. URL : http:// journals.openedition.org/mots/3483; DOI : https://doi.org/10.4000/mots.3483 


\section{Des mots en politique}

\section{Émotion populaire, petite note lexicologique}

[La chaussée] peut se muer en théâtre d'affrontements violents, de mouvements désordonnés, de courte durée certes mais aux effets traumatisants. [...] Les chroniqueurs emploient les mots évocateurs d'effrois, d'émois, d'émotions, de commotions, de communes, de tumultes, ou des expressions plus locales comme les rebeynes à Lyon, la harelle à Rouen (du cri haro!), la tricoterie à Angers (de tricot ou bâton), la mutemaque à Dijon, la miquemaque à Reims... ${ }^{1}$

Voilà bien émotion, commotion et même émoi, dans un curieux contexte sociohistorique, qui peut aller de la rixe de taverne à la commune insurrectionnelle! Bagarres avinées, querelles de quartier, guerres urbaines entre clans et parrains, paniques de la faim ou de l'épidémie, pogromes de juifs ou d'estrangiers, mises-bas par cabales et émeutes de grèves, révoltes contre le fisc, séditions assaillant le seigneur, l'évêque ou les agents royaux, etc. Jean-Pierre Leguay a raison de souligner la spontanéité populaire de ces soulèvements (ils sont le fait de «communes gens»), leur soudaineté et souvent leur courte durée, leur inorganisation apparente, leur violence surtout («Tuons, tuons tous les riches!» crient les révoltés de 1380 à Clermont-l'Hérault ${ }^{2}$ ). Acte collectif de revanche, l'émotion fait peur. Rétif de la Bretonne en est encore témoin au $18^{\mathrm{e}}$ siècle:

J'avoue que j'ai tremblé toutefois que j'ai vu la portion basse du peuple en émotion.

Et j'ai tremblé parce que je la connais, parce que je sais quelle est sa haine contre ce qui est aisé. (Les nuits de Paris, tome 2, 1788)

Par ailleurs, le mot émotion s'est, au cours des siècles, sémantiquement apparenté au vieux mot esmoi, peut-être par l'intermédiaire du participe passé-adjectif esmu, qui pouvait prendre les deux valeurs, physique et morale. Car s'esmaïer,

1. J.-P. Leguay, 1984, La rue au Moyen Âge, Rennes, Ouest-France-Université, p. 196.

2. Ibid. p. 200.

3. Cité par V. Milliot, La représentation de la ville à travers la littérature de colportage, mémoire de maitrise, université Paris 1, 1983, p. 142. 
au $12^{\mathrm{e}}$ siècle, signifie seulement s'inquiéter, être troublé, voire effrayé. Chez Chrétien de Troyes, esmai est glosé par peur: lorsque Énide est «esperdue» ou «esmue», ne sachant que faire, c'est en elle «grant peor et grant esmai» ${ }^{4}$.

Outre l'idée de mouvement de révolte, l'émotion, comme l'émoi, exprime couramment, à l'époque classique, des troubles affectifs, en particulier amoureux. La confusion des deux mots n'existait guère au Moyen Âge (à l'exception, on l'a noté, de l'adjectif esmu). On les rencontre en effet tous deux, par exemple dans le Roman de la Rose, avec deux significations très différentes. Des chevaliers montrent-ils du doigt une «damoisele» hésitante, Jean Renart écrit: «[ils] ne sevent pas son esmai» (ils ne se rendent pas compte de son trouble) ; pour sa part, esmovoir ne signifie, dans ce même roman, que pousser dehors, faire avancer: la venue du comte de Champagne est annoncée, avec tous ceux «qu'il a pu esmovoir» (c'est-à-dire mettre en route) $)^{5}$. Entre la réserve d'une demoiselle et la marche des chevaliers, pas de commune mesure?

Mais d'où viennent ces termes et cet usage si contradictoire, depuis le Moyen Âge, partagé qu'il est entre d'une part l'apitoiement sur soi et l'hésitation, souvent commandés par la crainte, et d'autre part l'élan, l'ébranlement, voire la brutalité, purement physiques.

La valeur physique de la mise en mouvement semble bien être première. Esmaïer et esmai / esmoi viendraient (par un verbe bas-latin, hypothétique, magare), comme l'allemand macht, l'anglais may, might, ou le français machine, d'une racine archaïque *magh- qui désignerait le pouvoir, la force. L'ajout du préfixe ex (d'où un hypothétique ex-magare) explique le renversement négatif du sens: smagare, en italien, veut dire se décourager et esmagar, en portugais, écraser. L'esmoi est ce qui rend faible, apportant le trouble, la crainte ou l'effroi. L'émotion (et l'émeute) dépendraient, elles, d'une autre racine plus archaïque encore *mov-/mot-, qui aurait désigné tout mouvement ou déplacement (sanskrit mivati : déplacer; latin movere, motum, d'où viennent mouvoir, mobile, meuble, moteur, motif, meute, etc.; anglais to move). Tel est le sens que traduit le verbe dès la Chanson de Roland: «Li amirals ki trestut les esmut» (l'émir qui les mit tous en branle).

Il y a toujours lien entre sentiment et action. C'est justement ce lien qu'émouvoir, avec esmeu, fait apparaitre. Jacqueline Picoche cite dans sa thèse l'expression «ému de», au sens de «désireux de $»^{6}$. Le sentiment de crainte retient,

4. M. Roques (éd.), 1953, Les romans de Chrétien de Troyes. Érec et Énide, Paris, Champion, vers 2521 et 2961 .

5. F. Lecoy (éd.), 1962, Le roman de la Rose ou de Guillaume de Dole, Paris, Champion, vers 4605 et 2089.

6. «Li rois de France, esmeus de contrevengier ces despis... », cité dans J. Picoche, 1972, Recherches sur le vocabulaire de Froissart. Le vocabulaire psychologique dans les Chroniques, Service des thèses, université de Lille 3, p. 192. 
mais celui de haine ou de vengeance pousse à faire. Froissart va même jusqu'à employer émouvoir en mêlant dans le verbe action et sentiment, donc avec le sens de soulever les passions du peuple, «exciter sa haine ou sa colère» (Picoche) en vue de «tourbler le royaume» :

Ces maleoites gens, pour mieux tourbler le royaume et esmouvoir le peuple, avoient mis en avant et semet ces paroles. Lors se commença li païs tous à esmouvoir et à effraer ${ }^{7}$.

Ce sens, très courant au $17^{\mathrm{e}}$ siècle, passe sur le substantif. Quand Corneille évoque les soulèvements de la "populace», c'est émotion qui vient sous sa plume: «Rome autrefois a vu de ces émotions» (Nicomède, acte 5, scène 2); le mot d'ailleurs s'accompagne de tumulte, se mutiner, mutin, fureur, confusion. Voilà pourquoi, collective, soudaine et brutale, l'émotion (populaire), synonyme d'émeute jusqu'à la fin du $18^{\mathrm{e}}$ siècle $^{8}$, a joint à sa dynamique, au fil du temps, les valeurs de l'émoi, qui s'était écarté d'elle. Au $18^{\mathrm{e}}$ siècle, le Journal d'un bourgeois de Paris sous le règne de Louis $X V$ ne fait-il pas usage du terme dans un emploi physique et social tout pénétré des connotations affectives qu'il manifeste dans d'autres sites d'emploi? Du trouble causé par l'injustice subie par soi, on passe aisément, à l'époque, à la révolte contre l'injustice subie par quelqu'un d'autre: la compassion engendre une révolte de la pitié et de la solidarité. Edmond Barbier raconte ainsi un jour de novembre 1721 :

Hier, il y eut grand tapage dans Paris. Un laquais [...] avait dit des sottises à sa maitresse. Il a été emmené au Châtelet et le procès a fini par une condamnation au carcan et aux galères. [...] Aussitôt que le poteau a été enfoncé, la populace s'est émue, on a brisé le poteau, le laquais a été ramené au Châtelet par les archers qui ont tiré quelques coups [...]. Tout ce quartier fut en émotion jusqu'à cinq heures du soir ${ }^{9}$.

Dans son ouvrage sur les soulèvements pendant l'Ancien Régime, Boris Porchnev donne plusieurs exemples de ce type d'emploi. Voici d'abord l'émotion assimilée à une querelle dégénérant en bagarre de rue: «L'esmotion n'est arrivée qu'en suite de ce qu'un habitant (un charretier) a été tué un peu légèrement par un des commis...» (Lettre de l'intendant de Champagne, 1643) ${ }^{10}$. Bien

7. Ibid., p. 244.

8. On trouve aussi le verbe émeuter: «Ils ont écrit des lettres circulaires pour émeuter les ouvriers des différentes fabriques » (Lettre à l'intendant de Castres, 7 juillet 1789), cité dans H. Tournier, 1925, Syndicats ouvriers et grèves révolutionnaires dans le Castrais à la fin de l'Ancien Régime, Toulouse, J. Bonnet, p. 66.

9. Cité par A. Farge, 1979, Vivre dans la rue à Paris au $18^{e}$ siècle, Paris, Gallimard-Julliard (Archives), p. 80-81.

10. B. Porchnev, 1972, Les soulèvements populaires en France au $17^{e}$ siècle, Paris, Flammarion, p. 240. 
plus graves sont les émotions expressions ou conséquences d'une «rebellion» au nom de la justice: «Icy les hommes se jettent à l'aveugle dans les rebellions si on les viole au-delà de la justice, et les émotions, les reproches de [faits aux] gabelleurs et les meurtres suyvent» (Lettre de l'intendant de Bordeaux, 1643) ${ }^{11}$.

Voici enfin l'émotion vue comme une sédition organisée, voire manipulée ${ }^{12}$ :

Tout est plein de sédition en France. Les parlements n'en châtient aucune [...]. Par conséquent, les séditions sont autorisées et je ne sais ce qu'il faut espérer ou appréhender de cela, vu la fréquence de ces émotions... (Lettre du chancelier Marillac à Richelieu, 1630) Les fréquentes émotions arrivées en plusieurs villes du royaume donnaient sujet d'en craindre les effets par la continuation de la guerre... (Mémoires de Richelieu) ${ }^{13}$

Elles sont si bien organisées, ces émotions qu'elles peuvent déboucher sur une révolte de grande ampleur, comme celles menées à Lyon par les ouvriers en soie, en 1744 (la rebellion des tireuses de corde) et en 1786 (l'émeute à deux sols $)^{14}$. Les canuts réclamaient déjà le tarif («prix» minimal d'une «façon») tout en sachant les difficultés de son application:

Sans un tarif, l'ouvrier est à la merci d'un marchand [...]. Mais un tarif a cet inconvénient $[\ldots]$ que plus on s'éloigne de l'époque où le tarif a été règlé, plus il devient désavantageux à l'ouvrier et plus le marchand résiste à une augmentation raisonnable: de là les émotions populaires telles que celle de 1786. (Mémoire des électeurs fabricants d'étoffes en soie de la ville de Lyon, 1789) ${ }^{15}$

Les émotions de ce type se multiplient à la fin du $18^{\mathrm{e}}$ siècle. Si Marat préfère parler à Paris d'émeute populaire ${ }^{16}$, les députés des tisseurs de soie à Lyon en tiennent pour émotion populaire, qui argumentent ainsi dès 1789:

L'assurance de n'être pas réduit à un prix inférieur [...] et l'espérance [d'obtenir justice de l'administration] calmera les maitres-ouvriers, préviendra les émotions populaires et les émigrations... (Mémoire relatif aux maitres-ouvriers fabricants d'étoffes [...] par Messieurs les seize députés de la ville et senéchaussée de Lyon, le 4 aout $1789)^{17}$

11. Ibid., p. 113.

12. Déjà, Calvin s'en défendait: «Ce ne sommes pas nous qui esmouvons les troubles» (cité dans Littré).

13. B. Porchnev, 1972, op. cit., p. 312-313.

14. Voir B. Clavel, 1992, La révolte à deux sous, Paris, Albin Michel.

15. J. Godart,1899, L'ouvrier en soie. Monographie du tisseur lyonnais, rééd. Genève, Megariotis reprints, 1976, p. 270-271, et F. Rude (éd.), 1976, Doléances des maitres-ouvriers adressées au Roi et à la Nation assemblée (1789), Lyon, Fédérop, p. 16 et 122.

16. «À quoi devons-nous la liberté qu'aux émeutes populaires? [...] C'est une émeute populaire formée aux Champs-Élysées qui a fait tomber la Bastille.» (Marat, Discours contre la loi martiale, 22 octobre 1789)

17. Cité dans F. Rude, Doléances, 1976, p. 38. 
Sauf archaïsme voulu, l'histoire sociale d'émotion, émeute et mutin s'arrête à la répression des barricades de juin 1848. Sédition, séditieux, rébellion et rebelle vont aussi céder la place. D'autres mots prennent le fil de l'histoire, au milieu du $19^{\mathrm{e}}$ siècle. Celle d'insurrection et d'insurgé est à faire, et, bien entendu, celle de grève et de gréviste, aux deux bouts - violence des armes ou non-violence des bras croisés - de la révolte populaire, dans cette «guerre perpétuellement déclarée aux Maitres-ouvriers [...] par la classe des Marchands $»^{18}$. C'est ainsi que l'émouvant mot d'émotion a pu nous conduire jusqu'au seuil d'une «guerre» de «classe».

18. Ibid, p. 81-82. 